\title{
Capital requirements, risk-taking and welfare in a growing economy
}

\author{
Pierre-Richard Agénor ${ }^{1}$ (D) Luiz A. Pereira da Silva ${ }^{2}$
}

Accepted: 5 August 2021 / Published online: 27 August 2021

(C) The Author(s) 2021

\begin{abstract}
The effects of capital requirements on risk-taking and welfare are studied in an overlapping generations model of endogenous growth with banking, limited liability, and government guarantees. Capital producers face a choice between a safe technology and a risky, more productive but socially inefficient, technology. Bank risk-taking is endogenous. As a result of a skin in the game effect—motivated either as an aggregate externality, or as the outcome of the optimal choice of monitoring effort by individual banks - default risk is inversely related to the capital adequacy ratio. Numerical simulations show that in an equilibrium where banks extend both safe and risky loans, the skin in the game effect must be sufficiently strong for a welfare-maximizing regulatory policy to exist. These results remain qualitatively similar with endogenous monitoring costs and a strong effect of monitoring on entrepreneurial moral hazard. However, numerical experiments also suggest that the optimal capital adequacy ratio may be too high in practice and may require concomitantly a broadening of the perimeter of regulation and a strengthening of financial supervision to prevent disintermediation and distortions in financial markets.
\end{abstract}

Keywords Capital requirements · Bank risk-taking · Bank monitoring · Endogenous growth $\cdot$ Optimal welfare analysis

\footnotetext{
Financial support to Pr. Agénor by the Financial Stability and Development Group is gratefully acknowledged. We are indebted to Ingo Fender, Hyun Song Shin, Leonardo Gambacorta, Daniel Osorio, participants at the BIS-IDB workshop on Financial Cycles and Policy Response in Latin America (Central Bank of Argentina) and an anonymous referee for many helpful discussions and comments, and to King Yoong Lim for research assistance. The views in this article are those of the authors and do not necessarily reflect those of the Bank for International Settlements. Appendices A and B are available upon request.
}

$凶$ Pierre-Richard Agénor pierre-richard.agenor@manchester.ac.uk

1 School of Social Sciences, University of Manchester, Manchester, UK

2 Bank for International Settlements, Basel, Switzerland 
JEL Classification E44 · G28 · O41

\section{Introduction}

The link between financial regulation, risk-taking, and the overall safety of the banking system has been studied in a number of contributions, which include Blum (1999), Diamond and Rajan (2000), Hellmann et al. (2000), Repullo (2004), Kopecky and VanHoose (2006), Gale (2010), Hakenes and Schnabel (2011), De Nicolò and Lucchetta (2014), and more recently Martinez-Miera and Suarez (2014), Malherbe (2015), and Gorton and Winton (2017). Much of this literature is based on partial equilibrium models and has focused on limited liability and (explicit or implicit) government guarantees, in addition to the degree of market competition, as key factors in creating incentives for banks to engage in excessive risk-taking in lending.

Several of these studies have also paid particular attention to the role of capital requirements - in the form of either simple leverage (asset-capital) ratios or risk-based charges - as a way to mitigate the incentives for risk-taking created by limited liability and government guarantees. Some have argued that increasing these requirements mitigate moral hazard problems and excessive (or, more specifically, socially suboptimal) risk-taking because shareholders have more skin in the game. Others, however, have reached opposite conclusions. For Diamond and Rajan (2000), for instance, capital requirements may have an important social cost because they reduce the ability of banks to create liquidity, whereas for Hellman et al. Hellmann et al. (2000) the skin in the game effect of an increase in capital requirements can be mitigated by the fact that it also reduces a bank's profit margin, thereby eroding its franchise value and inducing it to take on greater risks. More generally, as noted by Gale (2010), the view that capital requirements create incentives to avoid risks is often based on partial equilibrium analysis and ignores the factors that determine the supply and cost of capital. Indeed, in some of the contributions referred to earlier, capital regulation has no effect on asset returns, while in reality they (especially loan rates) respond to market forces that depend in part on the decisions that banks make when they are faced with changes in prudential regulation. In addition, when the cost of capital is high, forcing banks to raise more equity may actually lead to an increase in the probability of default and exacerbate risks to financial stability.

Although some of the early empirical literature on the impact of capital requirements on bank risk-taking appeared to be inconclusive (see, for instance, Laeven and Levine (2009)), recent studies have proved more supportive of a mitigating effect. In particular, Klomp and de Haan (2014), using cross-country data for the period 2002-08, found that stricter capital regulation reduces risk-taking in banking. ${ }^{1}$ Similar results have been established by Fratzscher et al. (2016) for a larger group of countries.

Somewhat surprisingly, there have been few contributions aimed at studying the longer-run implications (in terms of growth and welfare) of the interactions between financial regulation, risk-taking, and financial stability. This is important because finan-

\footnotetext{
1 They also found that the effect of regulation and supervision on risk-taking depends on the level of development, which may be a proxy for administrative capacity.
} 
cial regulation designed to reduce short-run procyclicality and mitigate the risk of financial instability could well be detrimental to economic growth in the longer run, as a result of their adverse effect on incentives to borrow and lend. In particular, while the immediate effects of raising capital standards may well be limited (especially if they are implemented gradually), in the longer run it may lead to higher market loan rates, a reduction in lending and investment, and substitution away from risky lending to holding safer assets, as a result of reduced risk incentives or lower resources devoted to monitoring. There may therefore be a potential dynamic trade-off, in terms of financial stability and growth or welfare, associated with prudential regulation. Understanding the terms of this trade-off is critical to optimally balance benefits and costs when setting prudential instruments.

This paper contributes to the ongoing debate on the impact that regulatory constraints may have on the risk-taking incentives of financial intermediaries in a growth context and how, as a result, they may lead to suboptimal levels of lending-with potentially adverse effects on social welfare. Specifically, the paper develops a twoperiod overlapping generations (OLG) model with competitive banking where growth is endogenized through an Arrow-Romer externality and capital-producing firms can use either a riskless technology or a risky production technology, which depends on an idiosyncratic shock. This setting allows us to assess, as in Nguyen (2015), for instance, the permanent effects of regulatory policy on growth and welfare, and not only level effects, as in Van den Heuvel and Skander (2008). In addition, as in Van den Heuvel and Skander (2008, 2018) and Collard et al. (2017), banks can make safe or risky loans to entrepreneurs, but the expected return on risky loans is decreasing in the probability of investment failure. Thus, the model focuses on financial fragility on the asset side of banks' balance sheets. Due to limited liability and implicit government guarantees, banks have incentives to engage in excessive risk-taking, that is, lending to risky and less efficient capital producers. Excessive risk-taking therefore involves the type, rather than the amount, of credit extended by banks. At the same time, banks are subject to capital requirements, which relate equity holdings and loans. In contrast to the partial equilibrium contributions referred to earlier, the cost of equity is determined endogenously and responds directly to changes in regulation.

Our analysis shows that, in the presence of a skin in the game effect-associated either with an aggregate externality, or viewed as an outcome of the optimal choice of monitoring effort by individual banks - the probability that projects fail is inversely related to the capital adequacy ratio. The key reason is that, as in Acharya et al. (2016) and Tanaka and Vourdas (2016), for instance, in the presence of government guarantees on deposits more capital mitigates banks' ex ante incentives to shirk on project monitoring, thereby mitigating the risk of failure of investment loans. Thus, capital requirements can generate direct benefits in terms of financial stability. The reason is that greater capital requirements induce banks to improve monitoring (given that they have more to lose in case of default), thereby fostering effort and due diligence on the part of borrowers. Numerical simulations along the balanced growth path show that in an equilibrium where banks extend both safe and risky loans, a welfare-maximizing regulatory policy exists if the skin in the game effect is sufficiently strong. Thus, our results complement those established by Hellmann et al. (2000) and Repullo (2004) in partial equilibrium models with moral hazard and imperfect competition in banking. 
However, our numerical experiments also suggest that the socially optimal capital adequacy ratio may be so high in practice that, due to competitive pressures, they may actually promote the development of shadow banking activities, which may eventually be detrimental to financial stability. To avoid these unintentional consequences, raising capital requirements may necessitate a concomitant strengthening of financial supervision and a broadening of the perimeter of regulation.

The remainder of the paper is organized as follows. Section 2 describes the economic environment and the behavior of agents, as well as the regulatory regime and the equilibrium conditions of financial markets. The balanced growth path is characterized in Sect. 3. The condition under which an equilibrium with safe loans only emerges is discussed in Sect. 4. The welfare-maximizing capital adequacy ratio is established numerically in Sect. 5. The analysis in Sect. 6 is extended to account for endogenous monitoring of risky loans, which provides a micro-foundation for the skin in the game effect, instead of viewing it as an aggregate externality. The last section provides some concluding remarks and discusses perspectives for further research.

\section{Economic environment}

The economy consists of a continuum of individual agents who live for two periods, adulthood (or young age) and old age, final goods producers, and a financial regulator. Population is constant and there is no aggregate uncertainty. Individual agents are all endowed with one period of time in adulthood and are of two types: an exogenous fraction $n \in(0,1)$ belongs to households, the remaining are entrepreneurs. Without loss of generality, $n$ is normalized to 0.5 and the measure of each type of agents to one. Households consist of a fixed number of individuals, which is also normalized to unity. When young (period $t$ ) each household member has one unit of time, which is sold inelastically in return for wage income $w_{t}$ denominated in final goods. At the end of period $t$, a fixed fraction $\varkappa \in(0,1)$ of household members are randomly selected to become bankers, who join together to form a bank, while a fraction $1-\varkappa$ becomes depositors. Thus, given that the number of households is normalized to unity, $\varkappa$ is also the share of bankers in the economy.

Each household divides $(1-\varkappa) w_{t}$ between period- $t$ consumption and saving via deposits, whereas $e_{t}=\varkappa w_{t}$ is used as equity, as in Foulis et al. (2019), for instance, to start the bank. ${ }^{2}$ Deposits can be held either at home or abroad; arbitrage implies therefore that both investments yield the same (gross) return, $R^{D}>1$, which is set on world markets. However, we also assume there is an (infinitesimally small) nonpecuniary benefit associated with holding assets closer to home; thus, although they are strictly indifferent, depositors prefer to hold all their savings in domestic banks. For simplicity, in each household there is full consumption insurance (that is, depositors and bankers of the same household share consumption equally) and banking involves no direct time cost.

\footnotetext{
2 In this growth setting, where all stock variables and wages grow at the same rate along the balanced growth path, the assumption that equity is a fixed fraction of wage income (and, thus, capital per worker, as shown later) ensures that the supply of equity grows also at the same constant rate.
} 
At the end of period $t$ bankers combine their equity with the deposits supplied by households to lend to risk-neutral entrepreneurs who invest to produce capital, using either one of two technologies. Capital becomes available at $t+1$ and is rented to final goods producers, who combine it with the labor time of the next generation, to produce a homogeneous final good at $t+1$. In period $t+1$ banks receive the return on the loans that they made in period $t$ and use it to pay back depositors, returning any profits lump-sum to the now old households, and close their doors. The new generation of young households, having received their wage, then form their own banks-which have no direct link to the previous banks - and the process repeats itself.

Entrepreneurs have no resource endowment; to produce capital goods, they must borrow from banks. ${ }^{3}$ As in Gale (2004), they cannot borrow directly from households. They have access to two alternative technologies to accumulate capital: one is safe and the other risky. Although (depending on the realization of an idiosyncratic shock) the risky technology may yield more capital than the safe technology when it succeeds, it yields no capital at all when it fails. Nevertheless, limited liabilitythe ability to default on loans in the event of failure-tempts entrepreneurs to use it. Entrepreneurs choose to use the safe technology or the risky technology before observing the realization of the idiosyncratic shock. As a result, banks are needed to monitor the entrepreneurs who claim to use the safe technology to ensure that they do so. Banks themselves, however, may have adverse incentives due to limited liability and implicit deposit guarantees, and these adverse incentives create a role for prudential regulation.

At the beginning of period $t$, entrepreneurs borrow from banks to finance investment and all agents (households, entrepreneurs, final goods producers, and banks) make their optimization decisions. Entrepreneurs using the risky technology are subject to a failure shock that is identically and independently distributed across them. The probability of failure (which is equal to the fraction of risky entrepreneurs who will eventually fail) is known up-front, but the identity of failing entrepreneurs is only discovered after the realization of the shock. That is, in the model, excessive risk-taking arises from limited liability and involves the type (rather than the amount) of credit extended by banks. Risk-taking is thus measured in terms of the composition of banks' loan portfolios.

Figure 1 summarizes the structure of the model and its timeline. In our setting, as in some of the existing literature, the need for capital requirements arises from limited liability and implicit deposit guarantees, which lead to excessive risk-taking. This involves the type of investments that banks are willing to finance because limited liability protects them from incurring large losses, and implicit guarantees dissociate their funding costs from their risk-taking. Sufficiently high capital requirements can always force banks to internalize the riskiness of their loans and thus mitigate risktaking behavior; the issue, however, is whether doing so entails a cost in terms of social welfare. In addition, although individual entrepreneurs are risky, banks themselves are not. Indeed, we assume that banks lend to a sufficiently diverse group of entrepreneurs that the uncertainty that exists in individual entrepreneurial loans washes out across loans. Thus, not only is there no uncertainty on deposit payments to households due to limited bank liability, but equity payoffs are not contingent either due to diversifi-

\footnotetext{
3 Thus, access to the international capital market is asymmetric: domestic agents can lend (deposit funds) but they can only borrow from domestic banks. The underlying assumption is that foreign lenders are at a disadvantage with respect to their ability to legally enforce the terms of loan contracts in domestic courts.
} 


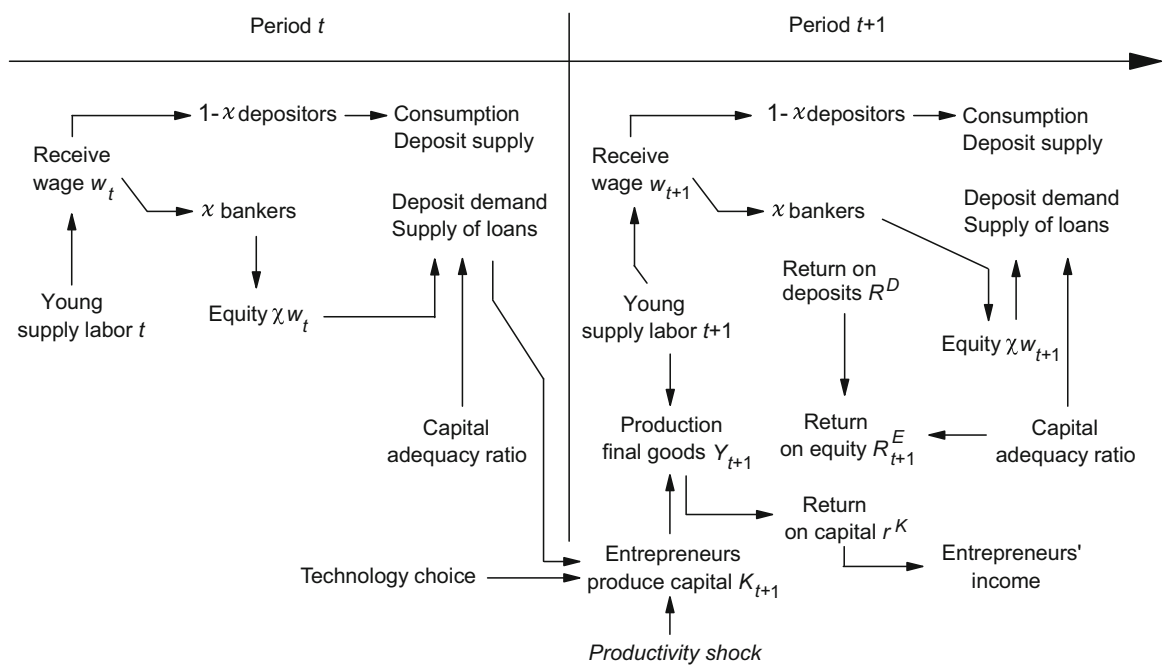

Fig. 1 Timeline of the economy

cation and the absence of aggregate uncertainty. Deposits and equity holdings, while imperfect substitutes (with the return on the first asset determined on world markets, and the return on the second determined through supply and demand equilibrium, as discussed later), are equally riskless to households.

\subsection{Households}

Households consume both in adulthood and old age. Utility $U_{t}$ of a household with all members born in period $t$ is given by

$$
U_{t}=\ln c_{t}^{t}+\Lambda \ln c_{t}^{t+1}
$$

where $c_{t}^{t+j}$ is consumption at $t+j, j=0,1$, and $\Lambda \leq 1$ is a discount factor.

As noted earlier, at the end of period $t$ a fraction $\varkappa$ (respectively, $1-\varkappa$ ) of household members becomes bankers (respectively, depositors). Deposits are fully guaranteed and their return is not state contingent. In addition, we assume that households can split their equity shares equally among all banks (other than their own), so that the law of large numbers applies and all idiosyncratic risks are diversified away. Thus, equity payoffs are not contingent and both deposits and equity are riskless to households.

The representative households period budget constraints are thus given by

$$
\begin{array}{r}
c_{t}^{t}+d_{t}=(1-\varkappa) w_{t}, \\
c_{t}^{t+1}=R^{D} d_{t}+R_{t+1}^{E} \varkappa w_{t},
\end{array}
$$


where $R_{t+1}^{E}$ is the return on equity. ${ }^{4}$

Solving the household's optimization problem yields the familiar Euler equation:

$$
\Lambda \frac{R^{D}}{c_{t}^{t+1}}=\frac{1}{c_{t}^{t}}
$$

which, combined with (2) and (3), gives optimal deposits as:

$$
d_{t}=\frac{\Lambda}{1+\Lambda}(1-\varkappa) w_{t}-\left(\frac{1}{1+\Lambda}\right) \frac{R_{t+1}^{E}}{R^{D}} \varkappa w_{t} .
$$

This equation shows that, all else equal, an increase in the return on deposits (equity) raises (lowers) the supply of bank deposits by households.

\subsection{Entrepreneurs}

Each entrepreneur $j$, with $j \in(0,1)$, is also born with one unit of labor time in adulthood, which is used to operate one of two types of technology, both of which can be used to convert units of final goods into a single capital good: a safe technology (identified with the superscript $S$ ), or a risky technology (identified with the superscript $R$ ), which is subject to an idiosyncratic shock. Because entrepreneurs have limited liability, those using the risky technology will default on their loans in the event of failure. ${ }^{5}$ All entrepreneurs produce the same type of capital good and are price takers. For simplicity, there is no aggregate uncertainty, investment entails no cost, and capital goods fully depreciate upon use.

Whatever the technology chosen, operating it generates no income in the first period. Entrepreneurs therefore do not consume in that period and derive utility only from their old-age consumption, $c_{t+1}^{j, F}$, which is equal to realized income in old age, $z_{t+1}^{j}$, which is derived later. Entrepreneurs are risk neutral and we therefore assume that their utility is linear in consumption:

$$
U_{t+1}^{j, E}=c_{t+1}^{j, F}
$$

Each entrepreneur invests the amount borrowed from banks, $l_{t}^{j}$. Thus, capital produced by an entrepreneur $j$ choosing the safe technology is given by ${ }^{6}$

$$
K_{t+1}^{j}=l_{t}^{j} .
$$

\footnotetext{
4 Although equity (equivalent to bonds in this setting) is acquired at $t$, its rate of return is dated $t+1$ to reflect when equity is repaid. As noted later, banks are competitive and make zero (expected) profits in equilibrium.

5 An entrepreneur has no incentive to diversify across multiple risky investments (or to combine risky and safe technologies) because in this setting the benefits of limited liability are maximized by undertaking a single risky investment.

6 Note that there is only one type of capital, even though there are two technologies for producing it.
} 
By contrast, entrepreneurs choosing the risky technology are subject to a failure shock, $\zeta_{t}^{j}$, which is independently and identically distributed across risky producers. Thus, if the investment is successful, capital is given by

$$
K_{t+1}^{j}=\zeta_{t}^{j}(1+\varepsilon) l_{t}^{j}
$$

where $\varepsilon>0$ is a productivity parameter which ensures that in the absence of failure the risky technology is always more productive than the safe one and, $\forall j$,

$$
\zeta_{t}^{j}=\left\{\begin{array}{ll}
0 & \text { with prob. } p \\
1 & \text { with prob. } 1-p
\end{array},\right.
$$

with $p \in(0,1)$ denoting the probability of failure, which is taken as given for the moment. The failure shock therefore has a discrete distribution with a mean value of $1-p$. Entrepreneur $j$ chooses whether to use technology $S$ or technology $R$ before observing the realization of the idiosyncratic shock $\zeta_{t}^{j}$.

Regardless of the technology used, entrepreneurs rent the capital that they produce to final goods producers at the beginning of period $t+1$. The return that they earn from renting is $R^{K}>1$, the (constant) marginal product of capital in a competitive equilibrium, as defined next.

This setup with two technologies serves to highlight a familiar connection between limited liability and excessive risk-taking: if entrepreneurs (borrowers) are not monitored properly, they may take on more risk than a hypothetical social planner would. For simplicity, using the risky technology to any degree is assumed to be always inefficient from the perspective of a social planner (the regulator in this setting), as formally stated next. Nevertheless, because of limited liability, entrepreneurs may still have an incentive to use it. There is therefore a need to monitor those who claim to use the safe technology, and only banks are assumed to have the skills needed to do so. ${ }^{7}$

To ensure that the risky technology is inefficient, and thus undesirable, from the regulator's perspective, the following condition is imposed:

Assumption $1(1-p)(1+\varepsilon)<1, \forall \varepsilon>0$ and $p \in[0,1)$.

The left-hand side of the condition stated in Assumption 1 represents the expected (gross) benefit of allocating one unit of investment to the risky technology, whereas the right-hand side is the (gross) opportunity cost, that is, the output of the safe technology.

Let the (gross) interest rate incurred when choosing technology $h=S, R$ and borrowing $l_{t}^{h}$ be denoted $R_{t+1}^{h} \cdot{ }^{8}$ Based on the previous equations, the following proposition can be directly established:

Proposition 1 Entrepreneurs are indifferent between the safe and risky technologies when the lending rate ratio is $R_{t+1}^{R} / R_{t+1}^{S}=1+\varepsilon$. No entrepreneur invests in the risky technology if $R_{t+1}^{R}>(1+\varepsilon) R_{t+1}^{S}$.

\footnotetext{
7 The fact that monitoring is necessary and requires specialized skills provides a rationale for the assumption that there is no direct intermediation from households to entrepreneurs.

8 The loan rate is agreed at time $t$ but is once again dated $t+1$, to reflect when loans are repaid. Thus, even with risky loans, the loan rate is not state contingent-it will not change in response to outcomes observed at time $t+1$.
} 
Indeed, an entrepreneur choosing the safe technology maximizes expected profits $R^{K} K_{t+1}^{j}-R_{t+1}^{S} l_{t}^{S}$ with respect to $l_{t}^{S}$, subject to (6); the solution is simply $R^{K}=R_{t+1}^{S}$. In the same vein, given limited liability, an entrepreneur choosing the risky technology maximizes $(1-p)\left(R^{K} K_{t+1}^{j}-R_{t+1}^{R} l_{t}^{R}\right)+p \cdot 0$ with respect to $l_{t}^{R}$, subject to (7). The (interior) solution is now $R^{K}(1+\varepsilon)=R_{t+1}^{R}$. Thus, entrepreneurs are indifferent between the two technologies when the first condition stated in Proposition 1 holds. By contrast, when $R_{t+1}^{R}>(1+\varepsilon) R_{t+1}^{S}$, no entrepreneur will find it profitable to invest in the risky technology and there will be no demand for risky loans.

Moreover, the model has no equilibrium with $R_{t+1}^{R}<(1+\varepsilon) R_{t+1}^{S}$. Indeed, if that condition were to hold, banks would have no incentive to fund risky investments, because safe investments would generate a higher return in every state of nature (that is, whatever the realization of the failure shock $\zeta_{t}^{j}$ ) and there would be no need to monitor them. ${ }^{9}$ Thus, given also that (from Proposition 1) there will be no demand for risky loans if the interest-rate ratio $R_{t+1}^{R} / R_{t+1}^{S}$ is strictly higher than the critical value $1+\varepsilon$, there is one and only one possible scenario under which entrepreneurs will use the risky technology - the case where they are indifferent between using either technology, $R_{t+1}^{R}=(1+\varepsilon) R_{t+1}^{S}$.

\subsection{Final output}

Competitive firms produce final goods (which can be either consumed or used as a production input) by combining labor and capital goods, which become available in each period before production starts. The underlying private technology exhibits constant returns in capital and labor inputs:

$$
Y_{t}=A_{t} N^{1-\alpha} K_{t}^{\alpha}
$$

where $\alpha \in(0,1), N$ is the number of workers (or household members), $K_{t}=\int_{0}^{1} K_{t}^{j} d j$ is the aggregate capital stock, and $A_{t}$ a productivity parameter.

There is an Arrow-Romer externality associated with the capital-labor ratio $k_{t}=$ $K_{t} / N$, so that

$$
A_{t}=A k_{t}^{1-\alpha}
$$

Combining (9) and (10) yields, in standard fashion, a linear relationship between (aggregate) production per worker, $y_{t}$, and capital per worker:

$$
y_{t}=A k_{t} .
$$

\footnotetext{
9 This property of the model, which is the same as in Collard et al. (2017), implies that there is no reason for banks to monitor entrepreneurs who claim to use the risky technology. Accordingly, only the cost to monitor safe technology users is accounted for in studying the behavior of banks later on. However, we extend the analysis later on to consider the case when monitoring of risky loans is endogenous and related to the default probability.
} 
Final goods producers operate in competitive output and input markets so that equilibrium capital rental and wage rates, $R_{t}^{K}$ and $w_{t}$, are determined by their marginal product:

$$
R^{K}=\alpha A, \quad w_{t}=(1-\alpha) A k_{t} .
$$

The following condition is imposed on $A$ :

Assumption $2 A>1 / \alpha$.

This condition ensures that the gross return to capital satisfies $R^{K}>1$.

\subsection{Banks and regulatory regime}

Banks last for two periods and their number is also normalized to unity. As noted earlier, a fraction $e_{t}=\varkappa w_{t}$ of each household's wage income is used to capitalize a bank. Using (12), the supply of equity is thus given by

$$
e_{t}=\varkappa(1-\alpha) A k_{t}
$$

Similarly, substituting equation (12) for $w_{t}$ in (4) yields the supply of deposits as

$$
d_{t}=\left\{\Lambda(1-\varkappa)-\frac{R_{t+1}^{E}}{R^{D}} \varkappa\right\}\left(\frac{1-\alpha}{1+\Lambda}\right) A k_{t} .
$$

The bank takes deposits from (other) households and combines them with its own resources to make safe and risky loans to entrepreneurs. Each bank extends risky loans to at most one entrepreneur employing the risky technology; this is because the benefits of limited liability are maximized by concentrating the risk in a single loan, given that this maximizes the probability of the worst outcome. ${ }^{10}$

Let $m^{S} \in(0,1)$ denote the exogenous marginal resource cost of monitoring an entrepreneur who claims to use the safe technology. The representative bank's resource constraint is

$$
l_{t}^{S}+l_{t}^{R}=e_{t}+d_{t}-m^{S} l_{t}^{S},
$$

where $m^{S} l_{t}^{S}$ represents the total cost of monitoring safe loans.

Given Assumption 1, risky investments reduce social welfare. To rule out the hypothetical case where risk-taking is directly prohibited by government fiat suppose, as in Van den Heuvel and Skander (2008, 2018) and Collard et al. (2017), that banks can hide some risky loans in their portfolio from the regulator. Specifically, let us assume that the regulator observes the total amount of loans made by each bank but cannot detect its risky loans up to a given fraction $\gamma \in(0,1)$ of its safe loans. ${ }^{11}$ It imposes

\footnotetext{
10 See Collard et al. (2017) for a further discussion.

11 In Van den Heuvel and Skander (2008), the threshold $\gamma$ is a decreasing function of the resources spent on bank supervision. Here it is assumed constant for simplicity.
} 
full capital requirements on risky loans above that fraction, $l_{t}^{R}-\gamma l_{t}^{S}$. The prudential regime is thus characterized by the following formula:

$$
e_{t} \geq \mu\left(l_{t}^{S}+l_{t}^{R}\right)+\max \left(0, l_{t}^{R}-\gamma l_{t}^{S}\right),
$$

where $\mu \in(0,1)$ is the capital adequacy ratio. Imposing full capital requirements on risky loans in excess of $\gamma l_{t}^{S}$ are such that they ensure that $l_{t}^{R} \leq \gamma l_{t}^{S}$ in equilibrium. ${ }^{12}$

We also assume (as noted earlier) that banks benefit from an implicit government guarantee on their deposits. Should their gross income from lending be insufficient to fully cover repayment to depositors, they benefit from a cost-free lump-sum transfer from the regulator, drawn from an initial endowment fund, to make up for the shortfall. ${ }^{13}$ The existence of this guarantee, together with the fact that (as shown later) equity is more expensive than deposit finance, ensures that banks will hold no more equity than required by regulation-or, equivalently, that they will choose as much leverage as allowed by the financial regulator. The prudential regime can consequently be equally characterized by the binding constraint on equity,

$$
e_{t}=\mu\left(l_{t}^{S}+l_{t}^{R}\right)
$$

together with the inequality constraint on risky loans,

$$
l_{t}^{R} \leq \gamma l_{t}^{S}
$$

As noted earlier, limited liability of risky borrowers implies that banks get nothing when projects fail. In addition, deposits are fully insured at no cost to banks and idiosyncratic risks are diversified away, implying that gross payments on deposits and equity represent full liabilities. Thus, expected bank profits when both types of lending occur can be defined as

$$
\max \left(0, \Pi_{t+1}\right)=\max \left[0, R_{t+1}^{S} l_{t}^{S}+(1-p) R_{t+1}^{R} l_{t}^{R}-R^{D} d_{t}-R_{t+1}^{E} e_{t}\right]
$$

Banks are perfectly competitive. They choose either $l_{t}^{S}$ only, or $l_{t}^{R}$ and $l_{t}^{S}$ jointly, to maximize (18) subject to (15), (16), and (17). ${ }^{14}$

12 In effect, the regulatory regime imposes a leverage ratio constraint paired with a risk sensitive surcharge. An additional dimension of risk sensitivity of the regulatory regime could be captured by replacing $\mu\left(l_{t}^{S}+l_{t}^{R}\right)$ by $\mu^{S} l_{t}^{S}+\mu^{R} l_{t}^{R}$, where $\mu^{S}, \mu^{R} \in(0,1)$ and $\mu^{R}>\mu^{S}$. However, this would make little substantive difference to the subsequent analysis, as long as $\mu^{R}$ is specified as a multiple of $\mu^{S}$. See Smith et al. (2017) for a model of capital requirements under a combined leverage ratio and risk-based charges, when banks hold both safe and risky assets.

13 As in Hellmann et al. (2000), Van den Heuvel and Skander (2008), and Gale (2010), for instance, bank contributions to that fund are abstracted from for simplicity. As long as these contributions are levied (and distributed) lump-sum, this assumption does not affect our welfare analysis. Note also that, by definition, there is no government guarantee with respect to equity funding from bank owners.

14 Strictly speaking, bank profits in (18) should be written as $\max \left(0, \Pi_{t+1}\right)$ given that profits can be negative. 
The solution of the representative bank's optimization problem is provided in Appendix A. A key implication of the solution of this optimization problem can be summarized in the following proposition:

Proposition 2 Either all banks take no risk $\left(l_{t}^{R}=0\right)$, or they take the maximum undetectable risk $\left(l_{t}^{R}=\gamma l_{t}^{S}\right)$. There are no equilibria with $0<l_{t}^{R}<\gamma l_{t}^{S}$.

The intuition, which is fundamentally the same as in Van den Heuvel and Skander (2008) and Collard et al. (2017), is as follows. If, given the loan portfolio, bank equity is sufficiently small to be wiped out when risky investments fail, then banks do not internalize the cost of additional risk-taking. Additional losses from increasing $l_{t}^{R}$, if risky investments fail, cannot occur as a result of limited liability and the implicit government guarantee on deposits. Consequently, the only equilibrium with the possibility of bank failure involves the outcome $l_{t}^{R}=\gamma l_{t}^{S}$. Alternatively, if bank equity is sufficiently large for banks to remain solvent even when risky investments fail, then banks would internalize the cost of additional risk-taking. In that case, given that the risky technology is (relatively) inefficient, banks can increase actual profits by reducing $l_{t}^{R}$. Accordingly, the only equilibrium without the possibility of bank failure requires $l_{t}^{R}=0$.

\subsection{Equity market equilibrium}

The return on equity, $R_{t+1}^{E}$, is solved to equilibrate supply and demand. As shown in Appendix A, the demand for equity by banks can be solved residually from the balance sheet and capital requirement constraints (15) and (16) to give

$$
\begin{aligned}
& e_{t}=\left(\frac{1+m^{S}}{\mu}-1\right)^{-1} d_{t}, \text { when } l_{t}^{R}=0 \\
& e_{t}=\left[\frac{1+m^{S}+\gamma}{\mu(1+\gamma)}-1\right]^{-1} d_{t}, \text { when } l_{t}^{R}=\gamma l_{t}^{S}
\end{aligned}
$$

with the supply of deposits given in (14). ${ }^{15}$

Equations (13) and (19), as well as (13) and (20), can be solved for the rate of return on equity. Appendix A shows that the solutions are

$$
\begin{aligned}
& \left.R^{E}\right|_{l_{t}^{R}=0}=\Phi_{1} R^{D}, \\
& \left.R^{E}\right|_{l_{t}^{R}>0}=\Phi_{2} R^{D},
\end{aligned}
$$

where

$$
\Phi_{1}=\frac{1+\Lambda}{\varkappa}\left\{\left(1-\frac{1+m^{S}}{\mu}\right) \varkappa+\frac{\Lambda(1-\varkappa)}{1+\Lambda}\right\},
$$

\footnotetext{
15 As shown next, banks accept all deposits that households are willing to make at the exogenous rate $R^{D}$, because deposits are cheaper than equity. Thus, the deposit market is always in equilibrium.
} 


$$
\Phi_{2}=\frac{1+\Lambda}{\varkappa}\left\{\left(1-\frac{1+m^{S}+\gamma}{\mu(1+\gamma)}\right) \varkappa+\frac{\Lambda(1-\varkappa)}{1+\Lambda}\right\}>\Phi_{1} .
$$

To ensure that (as stated earlier) banks will demand equity only up to the point at which the regulatory constraint (16) is binding requires imposing the following restriction:

\section{Assumption $3 \Phi_{1}>1$.}

This assumption (which ensures that $\Phi_{2}>1$ as well, given that $\Phi_{2}>\Phi_{1}$ ) guarantees that the rate of return on equity is always higher than the cost of deposits, as shown by the evidence (see Gambacorta and Shin (2018)). In turn, it ensures that households are always willing to supply the amount of equity $\varkappa w_{t}$, and that banks always prefer to finance themselves through deposits supplied by households. For Assumption 3 to hold, it can readily be shown that the share of wages allocated to equity cannot be too large. ${ }^{16}$

From (21) and (22), the following proposition can also be established:

Proposition 3 An increase in the capital adequacy ratio, $\mu$, raises the cost of equity, $d R^{E} / d \mu>0$.

Intuitively, for a given wage, the supply of equity is also given. A higher capital adequacy ratio therefore induces banks to cut back on lending. Given the banks' balance sheet constraint, the rate of return on equity must increase to induce households to reduce their supply of deposits, as can be inferred from (14) and either (19) or (20). ${ }^{17}$

\subsection{Bank lending spreads}

As shown in Appendix A, given (21) and (22), as well as Proposition 1, in equilibrium the loan spread is given by

$$
\begin{aligned}
& \left.\frac{R_{t+1}^{S}}{R^{D}}\right|_{l_{t}^{R}=0}=1-\mu+\mu \Phi_{1}+m^{S}, \\
& \left.\frac{R_{t+1}^{S}}{R^{D}}\right|_{l_{t}^{R}>0}=\frac{\left(1-\mu+\mu \Phi_{2}\right)(1+\gamma)+m^{S}}{1+(1-p) \gamma(1+\varepsilon)}=\Gamma,
\end{aligned}
$$

\footnotetext{
16 Specifically, the condition for both $\Phi_{1}$ and $\Phi_{2}$ to be greater than unity is $\varkappa<\mu \Lambda /(1+\Lambda)\left(1+m^{S}\right)$, which also ensures that $\varkappa \in(0,1)$. Intuitively, a higher $\varkappa$ reduces the demand for equity and therefore its rate of return. If that return is too high, the condition $R^{E}>R^{D}$ cannot be satisfied.

17 A number of other contributions to the literature on capital requirements, such as Gersbach (2013) and Gorton and Winton (2017), also predict a negative impact of higher bank capital requirements on bank deposits. At the same time, of course, the magnitude of the effect of the capital adequacy ratio on the cost of equity depends on the parameters of the model (including monitoring costs), and is therefore consistent with the evidence—reviewed by Cecchetti (2014), for instance—on a relatively small net effect.
} 
from which it can be established, under Assumptions 1 and 3, that $R_{t+1}^{S}>R^{D}$ in both equilibria. $^{18}$

Suppose that $p$ remains given for the moment. Under Assumption 3 and using Proposition 3, the following result can be directly established from (23) and (24):

Proposition 4 Under both equilibria, the spread between the safe interest rate and the deposit rate is increasing in the monitoring cost of safe loans, $m^{S}$, and in the capital adequacy ratio, $\mu$.

The effect of a higher monitoring cost of safe loans is straightforward. A higher capital adequacy ratio raises the loan rate under both equilibria because the regulatory constraint (16) implies that it raises the cost of funding for banks, that is, the return on equity; to keep profits constant, the loan rate must also increase. At the same time, at the initial level of equity, the level of loans (both safe and risky, given that $l_{t}^{R}=\gamma l_{t}^{S}$ ) must fall.

In addition, in the risky-loan equilibrium, the spread also depends on the detection threshold, $\gamma$, the probability of failure $p$, and the productivity of the risky technology, $\varepsilon$. In particular, the following results hold:

Proposition 5 In the equilibrium with risky loans, the spread between the safe interest rate and the deposit rate is increasing in the failure probability, $p$, and decreasing in the productivity of the risky technology, $\varepsilon$.

Intuitively, the dependence of the bank lending spread on the failure probability stems from the fact that making safe loans enables banks to make risky loans-given that hiding the risk associated with these loans is subject to the constraint $l_{t}^{R} \leq \gamma l_{t}^{S}$. The spread is decreasing in the productivity of the risky technology (conditional on it not failing) because a higher value of $\varepsilon$ raises risk-taking incentives for banks. However, given that risky loans are proportional to safe loans, both categories of loans fall.

\section{Balanced growth path}

To establish the balanced growth path, note first that, from (6) and (7), and appealing to the law of large numbers (given that $\zeta_{t}$ is independently and identically distributed across investments), the aggregate capital stock at $t+1$ is given by

$$
K_{t+1}=l_{t}^{S}, \text { when } l_{t}^{R}=0,
$$

18 Note also that in the model the loan rate is always set high enough for the bank to repay bankers, $R_{t+1}^{E} e_{t}$, that is, the restriction $R_{t+1}^{S} l_{t}^{S}+(1-p) R_{t+1}^{R} \gamma l_{t}^{S}-R_{t+1}^{E} e_{t} \geq 0$ always holds. Indeed, from (16), and (17) holding with equality, $e_{t}=\mu\left(l_{t}^{S}+l_{t}^{R}\right)=\mu(1+\gamma) l_{t}^{S}$. Thus the restriction is $R_{t+1}^{S}+(1-p) R_{t+1}^{R} \gamma-$ $R_{t+1}^{E} \mu(1+\gamma) \geq 0$. From (22) and Proposition $1, R_{t+1}^{E}=\Phi_{2} R^{D}$ and $R_{t+1}^{R}=(1+\varepsilon) R_{t+1}^{S}$, so the restriction becomes $R_{t+1}^{S}+(1-p) \gamma(1+\varepsilon) R_{t+1}^{S}-\Phi_{2} R^{D} \mu(1+\gamma) \geq 0$ or $R_{t+1}^{S} / R^{D} \geq \Phi_{2} \mu(1+\gamma) /[1+(1-p) \gamma(1+$ $\varepsilon)]$. But from (24), $R_{t+1}^{S} /\left.R^{D}\right|_{l_{t}^{R}>0}=\Gamma$; the sufficient condition is thus $\left(1-\mu+\mu \Phi_{2}\right)(1+\gamma)+m^{S} \geq$ $\Phi_{2} \mu(1+\gamma)$ or, equivalently, $(1-\mu)(1+\gamma)+\mu \Phi_{2}(1+\gamma)+m^{S} \geq \Phi_{2} \mu(1+\gamma)$. Upon simplification, this gives $(1-\mu)(1+\gamma)+m^{S} \geq 0$, which always holds. Thus, the specification of profits in (18) is consistent with limited liability of risky borrowers and the fact that deposits are fully insured at no cost to the banks. 


$$
K_{t+1}=[1+(1-p)(1+\varepsilon) \gamma] l_{t}^{S} \text {, when } l_{t}^{R}=\gamma l_{t}^{S} .
$$

Given that all banks behave in the same fashion, and that their number is normalized to unity, using (13) and (16) these equations yield

$$
\begin{aligned}
\frac{k_{t+1}}{k_{t}} & =1+g=\frac{\varkappa}{\mu}(1-\alpha) A, \text { when } l_{t}^{R}=0, \\
\frac{k_{t+1}}{k_{t}} & =\left[\frac{1+(1-p)(1+\varepsilon) \gamma}{1+\gamma}\right] \frac{\varkappa}{\mu}(1-\alpha) A, \text { when } l_{t}^{R}=\gamma l_{t}^{S} .
\end{aligned}
$$

Equations (25) and (26) define the steady-state growth rate of capital and, from (11), final output. In addition, given (13) and (14), equity and deposits grow at the same rate as well. A comparison of (25) and (26) shows that, given that from Assumption 1 $(1-p)(1+\varepsilon)<1$, the growth rate when both technologies are used is always lower than when only the safe technology is used. Thus, a policy that succeeds in promoting safe lending only would not create a trade-off between financial stability and growth.

Equations (25) and (26) also show that an increase in the capital adequacy ratio has an unambiguously negative impact on the growth rate in either equilibrium, essentially because (as discussed earlier) it raises the cost of, and lowers the demand for, credit. However, this result can be overturned by accounting for a skin in the game aggregate externality, assuming that individual banks do not internalize the effects of lending and bank capital on the probability of project failure (and thus the risk of default).

Specifically, suppose that skin in the game, as measured by the economy-wide (average) capital-loan ratio, induces banks to improve the degree of efficiency of their monitoring activities. ${ }^{19}$ In turn, improved monitoring, by fostering effort and due diligence on the part of borrowers (thereby mitigating entrepreneurial moral hazard problems), and by mitigating banks' moral hazard stemming from limited liability, reduces the probability of project failure and default on risky loans - as in Allen et al. (2011), Acharya et al. (2016), and Tanaka and Vourdas (2016), for instance. From (16) and (17), holding with equality, the capital-loan ratio is either $\mu$ when only safe loans are extended or $(1+\gamma) \mu$ when both types of loans are made. Thus, assuming for tractability a continuous function, this assumption yields

$$
p=p(\mu)
$$

with $p^{\prime}<0$ and $\lim _{\mu \rightarrow 1} p(\mu)<1$. If this effect is sufficiently large, tighter capital requirements could promote long-run growth-despite its adverse effect on the cost of, and the demand for, credit. Thus, when banks engage in risky loan activities, skin in the game provides a rationale for capital regulation in a growth setting as wellindependently of its impact on the probability or severity of financial crises. In that sense, our results complement those of Hellmann et al. (2000) and Repullo (2004). ${ }^{20}$

\footnotetext{
19 This assumption allows us to keep the unit cost of monitoring safe loans, $m$, constant for the sake of the argument. If $m$ also depends on the capital-loan ratio, our analysis would remain the same as long as the effect on the benefit of increased monitoring dominates.

20 An alternative derivation of the relationship between the default probability and the capital requirement ratio is discussed later, in the context of optimal monitoring choices.
} 


\section{Regulation and the prudent equilibrium}

The next issue to address is to determine the conditions under which the equilibrium with safe loans only_or what Hellmann et al. (2000) and Repullo (2004) refer to as the prudent equilibrium - prevails. Given limited bank liability, for risky lending to occur, ex ante banks must make a nonnegative expected profit when risky loans are made. As shown in Appendix A, holding $p$ constant, and given Propositions 1 and 2, the following result can be established:

Proposition 6 For only the prudent equilibrium to prevail, a necessary and sufficient condition is $(1-p) \gamma(1+\varepsilon) \Gamma-\left[(1-\mu) \gamma+\mu(1+\gamma) \Phi_{2}-\mu \Phi_{1}\right] \leq 0$.

The condition stated in Proposition 6 is rather complicated and not particularly informative. The issue however is whether the regulator can set the capital adequacy ratio in such a way that it achieves financial stability, in the sense of ensuring that banks abstain from making risky loans.

Because $\Gamma, \Phi_{1}$ and $\Phi_{2}$ all depend on $\mu$, an explicit analytical solution is difficult to establish. The reason is that an increase in $\mu$ tends to raise both intermediation costs (through its impact on the cost of equity, as noted in Proposition 3) and revenue from loans (through its positive impact on the loan rate, as stated in Proposition 4). Thus, whether a higher $\mu$ contributes to making the inequality in Proposition 6 more likely to hold or not depends in general on the relative significance of the income and cost effects, or equivalently whether the pass-through is complete or incomplete.

To gain insight on this issue we therefore turn to a simple numerical calibration, assuming that the time period is one year. ${ }^{21}$ The discount factor is set at 0.961 , corresponding to an annual discount rate of 4 percent. We set $p=0.136$ and $m^{S}=0.012$, based on the quarterly estimates of 0.034 and 0.003 , respectively, provided by Collard et al. (2017, Table 1). We also set $\varkappa=0.048$ and $\gamma=1.0$, to capture a risky environment. The combination of these values ensures that Assumption 3 is satisfied. In addition, for $p$ given, Assumption 1 imposes an upper bound on the productivity parameter $\varepsilon$, that is, $p /(1-p)$. We thus vary $\varepsilon$ from a fairly low value of 0.01 to a value close to, but strictly less than, its upper bound. Experiments within that range show that when $\varepsilon$ is sufficiently low, the cost effect dominates, and the threshold value of $\mu$ (for which the condition in Proposition 6 holds with equality) is positive. By contrast, when $\varepsilon$ is relatively high, the threshold may turn negative. Moreover, in the first case the threshold can be close to unity.

Thus, although it is theoretically possible to set $\mu$ high enough to eliminate incentives for banks to make risky loans, this is a feasible only under specific circumstances - which in practice may be difficult for the regulator to identify. Moreover, what we observe in the real world is that banks make both safe and risky loans. Accordingly, in what follows we will consider only the equilibrium where both types

\footnotetext{
21 In this paper, as in a number of other contributions, the OLG structure is used for conceptual clarity. However, the intended period length is not truly a generation-or 25 to 30 years as is often the case with OLG models. Indeed, although these models have long been used to study monetary and financial issues in a growth context, the assumption that loans are made in $t$ and repaid in $t+1$ cannot be taken literally as referring to two generations. Moreover, from the perspective of linking the analysis to regulatory policy in the real world, a period is best interpreted as being of the order of one year.
} 
of loans are made and focus on the determination of the socially optimal value of the capital adequacy ratio.

\section{Optimal capital requirements}

Consider now the case where the regulator (just like a social planner) is far-sighted and benevolent and sets the capital adequacy ratio in the equilibrium with both safe and risky loans to maximize the welfare of all current and future generations of entrepreneurs and households.

To calculate the welfare for each generation, recall that while households consume in both periods, entrepreneurs consume only in adulthood. Thus, $c_{t+1}^{F}=z_{t+1}$, where $z_{t+1}$ denotes an entrepreneur's realized income in old age. In turn, an entrepreneur's expected income if the risky technology is chosen (and thus $l_{t}^{R}=\gamma l_{t}^{S}$ ) is $(1-$ p) $\left(R^{K} K_{t+1}-R_{t+1}^{R} l_{t}^{R}\right)$, so that using (7), (12), (16) and (24), as well as Proposition 1,

$$
z_{t+1}=\left\{\alpha A-(1+\varepsilon) \frac{\left[\left(1-\mu+\mu \Phi_{2}\right)(1+\gamma)+m^{S}\right]}{[1+(1-p) \gamma(1+\varepsilon)]} R^{D}\right\} \frac{(1-p) \gamma}{\mu(1+\gamma)} e_{t} .
$$

Using (5) and (13), an entrepreneur's indirect utility function is thus

$$
V_{t+1}^{F}=V_{m}^{F}(\mu) k_{t}
$$

where

$$
\begin{aligned}
V_{m}^{F}(\mu)= & \left\{\alpha A-\frac{(1+\varepsilon)\left[\left(1-\mu+\mu \Phi_{2}\right)(1+\gamma)+m^{S}\right]}{[1+(1-p) \gamma(1+\varepsilon)]} R^{D}\right\} \\
& \times(1-p) \gamma \frac{\varkappa(1-\alpha) A}{\mu(1+\gamma)} .
\end{aligned}
$$

For households, given that there are no bequests, Appendix A shows that their indirect utility function takes the form

$$
V_{t}^{H}=V_{m}^{H}(\mu)+(1+\Lambda) \ln k_{t},
$$

where, given that $\Phi_{2}$ depends on $\mu$,

$$
V_{m}^{H}(\mu)=\ln \left[\frac{\left(1-\varkappa+\varkappa \Phi_{2}\right)(1-\alpha) A}{1+\Lambda}\right]+\Lambda \ln \left[\frac{\Lambda\left(1-\varkappa+\varkappa \Phi_{2}\right) R^{D}(1-\alpha) A}{1+\Lambda}\right] .
$$

Recall that each group represents half of the population. Thus, the welfare criterion is the equally weighted sum within each generation, but discounted sum of utility across an infinite sequence of generations (see De la Croix and Michel, 2002, p. 91):

$$
\mathcal{W}=0.5 \sum_{h=0}^{\infty} \Omega^{h}\left(V_{t+h+1}^{F}+V_{t+h}^{H}\right)
$$


where $\Omega \in(0,1)$ is the regulator's discount factor. From (28 ) and (29), along the balanced growth path,

$$
\mathcal{W}=0.5 \sum_{h=0}^{\infty} \Omega^{h}\left[V_{m}^{F}(\mu) \tilde{k}_{t+h}+V_{m}^{H}(\mu)+(1+\Lambda) \ln \tilde{k}_{t+h}\right] .
$$

From (26), $k_{t}$ grows at a constant rate, $1+g$, along the balanced growth path. Thus, along the steady-state equilibrium path, $\tilde{k}_{t+h}=(1+g)^{t+h} k_{0}$. Substituting this result in (31) yields, setting $k_{0}=1$,

$$
\mathcal{W}=0.5 \sum_{h=0}^{\infty} \Omega^{h}\left\{V_{m}^{F}(\mu)(1+g)^{t+h}+V_{m}^{H}(\mu)+(1+\Lambda)(t+h) \ln (1+g)\right\} .
$$

Given that $\Omega<1$, solving (32) gives, with $t=0,{ }^{22}$

$$
\mathcal{W} \simeq \frac{V_{m}^{F}(\mu)}{1-\Omega(1+g)}+\frac{V_{m}^{H}(\mu)}{1-\Omega}+\frac{\Omega(1+\Lambda)}{(\Omega-1)^{2}} \ln (1+g),
$$

with $1+g$ given in $(26)$ and $\Omega(1+g)<1$. The optimal value of $\mu$ is the one for which $d \mathcal{W} / d \mu=0$ is obtained.

Although an explicit analytical solution to this optimization problem cannot be derived, it is worth highlighting the different channels through which $\mu$ affects welfare. Consider $V_{m}^{F}(\mu)$; the first term in brackets in that expression depends negatively on $\mu$ because an increase in the capital adequacy ratio raises the rate of return on equity (as implied by Proposition 3) and therefore the cost of borrowing. By implication, it lowers entrepreneurial income and consumption. The second term in that expression, which reflects the fact that (at a given supply of equity) a higher capital adequacy ratio lowers the supply of loans, depends also negatively on $\mu$.

Next, consider $V_{m}^{H}(\mu)$; here, the increase in the rate of return on equity has a positive effect on second-period income (given that $R^{E}>R^{D}$ ) and therefore on household consumption today and tomorrow.

Finally, there is a growth effect through $1+g$. An increase in the capital ratio has a negative impact on growth by reducing lending and investment for a given probability of failure. But in addition to this direct effect, as noted earlier, there may also be a skin in the game externality when the probability of project failure, and thus the risk of default, is endogenous: a higher capital adequacy ratio tends to reduce the risk of failure, which leads to a lower loan rate and a higher supply of loans. Thus, there is also a positive effect on growth, as well as on entrepreneurial income through $V_{m}^{F}(\mu)$. The optimal value of $\mu$ balances out these positive and negative effect on social welfare.

To illustrate possible outcomes we solve for the optimal capital adequacy ratio, based on (31), through numerical simulations. Assuming the same discount factor

\footnotetext{
22 This derivation uses the standard results $\sum_{h=0}^{\infty} x^{h}=1 /(1-x)$ and $\sum_{h=0}^{\infty} h x^{h}=x /(x-1)^{2}$ when $|x|<1$.
} 
for households and the regulator, so that $\Omega=\Lambda$, all the values provided earlier for $\Lambda, p, m^{S}, \varkappa$, and $\gamma$ remain the same. In addition, we assume that the elasticity of output with respect to capital is set at $\alpha=0.35$ - a fairly standard value, based on the estimation of aggregate production functions-whereas the (real) gross deposit rate is set at $R^{D}=1.02$. These values are fairly standard. The productivity parameter $\varepsilon$ is set at a relatively low value, 0.032 , to ensure that the cost effect of an increase in $\mu$ (as discussed earlier) dominates. We also set $A=4.5$, to make sure that Assumption 2 is satisfied. Finally, to account for the skin in the game effect, as captured in (27), we use the simple functional form $p=1-a_{0} \exp \left(-a_{1} \mu\right)$, with $a_{1}>0$ and $a_{0}$ set to ensure that $p$ is equal to the value stated earlier, 0.136 , when $\mu=0.01$ (the starting value for our experiments). ${ }^{23}$

Consider first the case where $p$ is constant. Experiments show that in such conditions welfare is continuously decreasing in $\mu$ over the interval $(0,1)$. Put differently, in the absence of a moral hazard benefit associated with regulation, the negative effects on social welfare alluded to earlier tend to dominate; the optimal policy is to set $\mu$ (close) to 0 .

Suppose now that there is a skin in the game externality, as captured in (27). Experiments show that now if $a_{1}$ is sufficiently large (namely, $a_{1}>3$ ) an interior solution for the optimal value of $\mu$ can be obtained. Indeed, the determination of the optimal capital adequacy ratio for $a_{1}=6.5$ is illustrated in Fig. 2, which shows that the relationship between social welfare (scaled by its base value when $\mu$ is 0.01 , that is, corresponding essentially to the absence of regulation) and the capital adequacy ratio. The figure shows that this relationship has an inverted-U shape and that the optimal value is $\mu=0.33$, with a corresponding value of $p=0.031$. With a value of $a_{1}=12$, $\mu=0.18$. Although in both cases the optimal capital adequacy ratio is higher than the Common Equity Tier 1 capital ratio set under the Basel Accord for 2013 (see Basel Committee on Banking Supervision (2011, Annex 2)), it illustrates well the forces at play. ${ }^{24}$ In addition, the latter estimate is close to the optimal risk-based capital ratio calibrated in other studies, such as Begenau (2015), Begenau (2016), and Boissay and Collard (2016), all using a different methodology.

Intuitively, increases in the capital adequacy ratio improve welfare at first because the drop in the probability of project failure reduces the cost of loans, which has a positive effect on entrepreneurial income and mitigates the direct impact of a higher ratio on the cost of equity (or equivalently the cost of borrowing for entrepreneurs) and the supply of loans. Even though the skin in the game effect (the reduction in $p$ ) is not large enough, given our calibration, to ensure that the net effect on lending and investment is positive, household consumption (which is positively affected by a higher return on equity) and welfare tend to increase. However, as $\mu$ continues to rise the marginal benefit of a reduction in the probability of project failure and default weakens; its adverse effect on the cost of borrowing, investment, and growth tends

\footnotetext{
23 A value of $\mu$ exactly equal to 0 is not feasible in the simulation, given the way $\mu$ enters in some of the equations to be solved (see (26) for instance). An alternative simple functional form, used in the next section, is $p=1-a_{0}-a_{1}(1+\mu)^{-1} \mu$, with $a_{0}, a_{1} \in(0,1)$ and $a_{0}+a_{1}<1$. It gives qualitatively similar results.

24 The Common Equity Tier 1 ratio is the relevant concept for comparative purposes, given the model's simplified bank capital structure.
} 


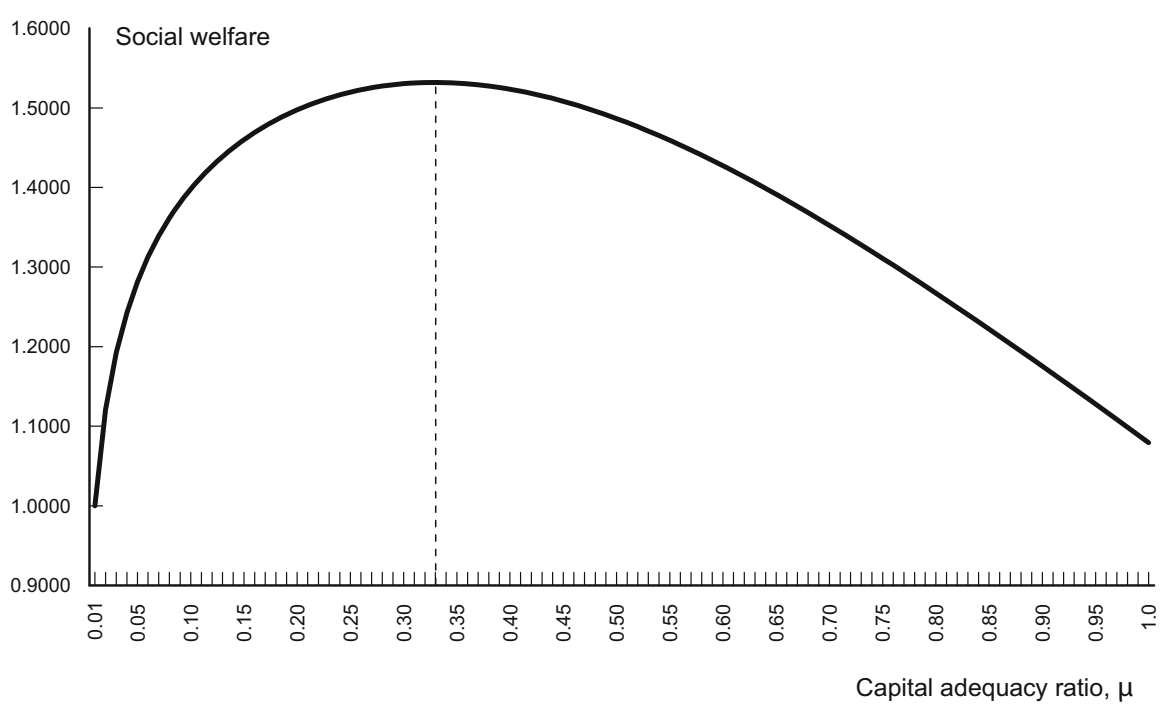

Source: Authors' calculations.

Note: Social welfare is normalized by the initial value of welfare for $\mu=0.01$.

Fig. 2 Welfare and optimal capital adequacy ratio equilibrium with risky loans

eventually to dominate. The optimal capital adequacy ratio is pinned down at the point at which its marginal effect on welfare is zero. ${ }^{25}$

The experiments reported in Fig. 2 are largely illustrative and subject to obvious limitations. In particular, the choice of the functional form relating the probability of project failure and the capital adequacy ratio, although intuitive, is somewhat arbitrary. In addition, the need to satisfy Assumptions 1 and 3 impose restrictions as to the range of parameter values that can be considered for sensitivity analysis, although changes in some of them $\left(m^{S}, \gamma\right.$, and $\Omega$, in particular) have very little or fairly intuitive impact on the results. ${ }^{26}$ The absence of transitional dynamics also means that welfare was evaluated only along the balanced growth path.

Nevertheless, these results help to illustrate three key points of the analysis. First, in an environment where bank incentives to provide risky loans cannot be eliminated entirely, maximizing welfare can generate benefits in terms of financial stability (by reducing the risk of project failure and the probability of default on these loans) if the regulator internalizes the impact of its decisions on risk-taking incentives. Second, for

\footnotetext{
25 The linearity assumption of the production function of final goods implies that the rental rate of capital is constant and independent of regulatory policy. By contrast, with decreasing marginal returns, the rental rate of capital would be inversely related to the capital stock, and would therefore be indirectly affected by the amount of loans and risk-taking. With investment falling, the rate of return on capital would increase, thereby raising entrepreneurial income. However, welfare analysis would be more involved and we would not be able to assess the permanent effects of regulatory policy on growth.

26 A lower marginal monitoring cost $m$ raises the optimal value of $\mu$. Intuitively, a lower monitoring cost lowers the cost of borrowing while increasing entrepreneurial income and investment; as a result, maximizing welfare requires a higher capital adequacy ratio.
} 
that to occur, the moral hazard externality associated with financial regulation must be strong enough for an optimal policy to exist. This is in line with formal and informal arguments regarding the benefits of capital requirements in partial equilibrium settings (see Hellmann et al. (2000), Repullo (2004), and Dagher et al. (2016)). Third, when it exists the optimal capital adequacy ratio may be fairly high, compared to the 10-12 percent range considered in the Basel Accords. These high values, if implemented, could foster disintermediation and the expansion of the shadow financial systemthereby exacerbating the very financial risks that capital requirements are supposed to address in the first place. $^{27}$

\section{Monitoring and skin in the game}

In the foregoing analysis, we assumed that banks only monitor entrepreneurs who claim to use the safe technology, and that the skin in the game effect results from an aggregate externality associated with capital requirements. In Appendix B we generalize the analysis to account for monitoring costs on risky loans and for the case where banks choose the degree of monitoring on these loans optimally. We also assume that, the probability of project failure (and default) is directly and inversely related to monitoring effort - a standard approach in the banking literature, as in Allen et al. (2011) and Dell' Ariccia et al. (2014), for instance. ${ }^{28}$ Thus, we now have $p=p\left(m^{R}\right)$, where $m^{R}$ is monitoring effort, with $p^{\prime}<0$. In Appendix B, a simple and fairly general functional form that captures this relationship, while ensuring that $p$ is bounded between 0 and unity, is specified, with in addition $p(0)=1 .{ }^{29}$ Thus, with no monitoring, risky projects always fail. In this setting, banks choose both the lending rate (as before), and monitoring effort, $m^{R}$.

As also shown in Appendix B, and abstracting from monitoring of safe loans $\left(m^{S}=\right.$ 0 ), the solution of the model gives now an implicit expression for $m^{R}$ as a function of $\mu$, $F\left(m^{R}, \mu\right)=0$. Applying the implicit function theorem, it can be shown that in general an increase in the capital requirement ratio has an ambiguous effect on the optimal intensity of monitoring. For a given intensity of monitoring, an increase in $\mu$ raises the loan spread (as discussed earlier), and therefore the optimal intensity of monitoring. At the same time, however, the increase in monitoring itself has an ambiguous impact on the spread. On the one hand, it raises the spread, through a direct cost effect, given that monitoring reduces the amount of resources that banks can lend-while at the same time paying interest on deposits. On the other, it lowers the default probability, which tends to reduce the loan rate, because the expected return to lending increases. If the

\footnotetext{
27 Begenau (2016) reach a similar conclusion with respect to capital requirements in a short-run model that features both regulated and unregulated (shadow) banks.

28 As noted by Allen et al. (2011, p. 988-89), this setting captures the view that banks observe information about the firms thet lend to and then use it to help improve the firm's performance. Alternatively, it captures the idea that entrepreneurs and banks have complementary skills: the former have an expertise in running the firm, whereas the latter provide financial expertise that helps improve the firm's expected value. The important point is that greater monitoring is desirable from the borrower's perspective, not simply from the lender's.

29 An exponential form similar to the one used earlier for the numerical experiments, $p=1-$ $a_{0} \exp \left(-a_{1} m^{R}\right)$, is less tractable to address the issue at stake.
} 
moral hazard effect is strong enough, the net effect of increased monitoring on the loan rate will be negative, which implies that the impact of a higher capital requirement ratio will unambiguously increase the optimal degree of monitoring. If an increase in $\mu$ raises the optimal intensity of monitoring, then it will also reduce the probability of default and generate an effect similar to the skin in the game effect alluded to earlier. Thus, the simpler specification used earlier, $p=p(\mu)$ with $p^{\prime}<0$, and based on an aggregate externality, is also consistent with micro-founded optimal behavior by banks when monitoring effort is endogenous and affects directly the probability of default. By implication, the qualitative features of the welfare-maximizing analysis carried out in the previous section would continue to hold in that case.

The foregoing analysis assumed that bank monitoring directly determines the probability of default - an assumption that captures the idea that monitoring is desirable for borrowers who invest in the risky technology. At the same time, we have abstracted so far from the possibility that borrowers, by exerting effort, may improve the likelihood of success of their investment - should they choose to use the risky technology. In line with Holmström and Tirole (1997), and as in Allen et al. (2011), suppose that the probability of default depends now on the borrower's effort. In particular, suppose that the borrower chooses an unobservable effort level $\theta \in(0,1)$, which determines the probability of default, so that $p=p(\theta)$ with $p^{\prime}<0$, and carries a cost of $\theta^{2} / 2$. The borrower also enjoys a (nonpecuniary) private benefit $(1-\theta) B>0$, which is maximized when he or she exerts no effort. ${ }^{30}$ Thus, in this framework, bank monitoring - which can be thought of here as taking the form of using accounting and other controls to reduce the amount of time the borrower can spend pursuing privately beneficial activities - influences the likelihood of success of investment projects only indirectly, by helping to alleviate entrepreneurial moral hazard. In particular, the bank chooses a monitoring effort $m^{R}$, which reduces the private benefit of the borrower to $(1-\theta) B\left(1-m^{R}\right)$ and entails either a linear cost (as before) or a quadratic cost, $\left(m^{R}\right)^{2} / 2$.

Assuming that monitoring is chosen before the borrower's effort, it is easy to show, following the analysis in Allen et al. (2011, pp. 1004-5), that the borrower's effort will be increasing in the intensity of monitoring. ${ }^{31}$ Thus, as before, bank monitoring positively affects the success probability of investments in the risky technology, this time because it reduces moral hazard. The difference is that, in setting the loan rate, the bank must now consider also the negative effect that this has on the borrower's optimal level of effort. But as long as this effect is not too large, the previous results will continue to hold. By implication, so will the qualitative features of our previous welfare-maximizing analysis.

\footnotetext{
30 As noted by Allen et al. (2011, p. 1004), one way of interpreting the cost $-\theta B$ is that effort reduces the amount of time the borrower can spend pursuing privately beneficial activities.

31 Formally, in the present setting the borrower who chooses to invest one unit in the risky technology chooses his or her effort to maximize $\theta\left[(1-p)\left((1+\varepsilon) R^{K}-R^{R}\right)\right]+(1-\theta) B\left(1-m^{R}\right)-0.5 \theta^{2}$. For $p$ given, the solution is $\theta=\min \left\{(1-p)\left((1+\varepsilon) R^{K}-R^{R}\right)-B\left(1-m^{R}\right), 1\right\}$. Thus, a higher $m^{R}$ raises $\theta$, which in turns lowers $p$, thereby further increasing $\theta$.
} 


\section{Concluding remarks}

This paper studied, in a growth model where banks are the only institutions engaged in financial intermediation, the welfare effects of banking regulation in the form of capital requirements, which indirectly act as a constraint on banks' portfolios. Because equity is more expensive than deposits, banks choose the minimum amount of capital that is compatible with the capital requirement rule. Entrepreneurs borrow from banks to invest in either a safe or a risky technology but are protected by limited liability.

The main results of the analysis were summarized in the introduction. In a nutshell, they show that, in ans economy where banks extend both safe and risky loans, the skin in the game effect associated with capital requirements-motivated either as an aggregate externality, or as the outcome of the optimal choice of monitoring effort by banks at the individual level—can generate benefits in terms of financial stability (by reducing default risk on the part of borrowers) but it must be sufficiently strong for a welfare-maximizing regulatory policy to exist. In addition, our numerical experiments suggest that the optimal capital adequacy ratio may be too high in practice and may need to be accompanied by a strengthening of financial supervision to avoid a situation where (as in Begenau (2016), for instance) risks migrate from banks to lightly regulated nonbank financial intermediaries - making the financial system, in the end, more prone to instability.

Our analysis can be extended in several directions. First, in the model, risk taking is exclusively related to the type of credit extended by banks. One extension could be to modify our setup to consider situations in which both the type and the volume of credit matter. To do so the cost of originating and monitoring safe loans could be related positively to the aggregate volume of these loans, as in Christensen et al. (2011) and Agénor (2019), for instance. As a result, shocks that affect the volume of safe loans would also affect the cost of these loans and thus banks' risk-taking incentives. Second, the model could be made more realistic by accounting for the possibility of efficient risk-taking. To do so would involve adding a third technology that is risky but can be efficiently combined with the safe technology. However, this would add require solving a more complex portfolio problem. Third, as noted earlier, raising capital requirements may necessitate a concomitant strengthening of financial supervision and a broadening of the perimeter of regulation, to prevent a growth in shadow banking. It would be useful to study how a combination of regulatory tools can achieve this objective. Fourth, in our model the distribution of individuals between households and entrepreneurs was taken to be exogenous; a possibly fruitful extension would be to endogenize the decision to become and entrepreneur and study the extent to which it depends on access to credit-whose cost depends on prudential regulation. This would therefore provide another channel through which capital requirements affect long-term growth. Fifth, our analysis has relied to a large extent on specific functional forms for tractability. The clarity that this provides, in terms of being able to derive explicit analytical results, are in our view well worth the loss of generality. Nevertheless, it could be useful to consider more general assumptions with possibly greater reliance on numerical simulations.

Yet another extension would be to introduce explicitly risk-based deposit insurance premiums and to determine if, as argued by Rochet (1992), for instance, these 
premiums are a more effective instrument for reducing portfolio risk than capital requirements. in addition, it may be important to account for adverse selection. Indeed, if higher capital requirements lead to higher lending rates, it may attract lower-quality borrowers who are willing to pay a high price for their loans, in Stiglitz-Weiss fashion. This may magnify financial risks. If banks choose to satisfy higher capital requirements by raising equity, lending may decline and the riskiness of bank loans may increase, instead of falling. Thus, paradoxically, capital requirements could make banks riskier than they would be in the absence of such requirements.

Finally, our social welfare analysis, in standard fashion, used a utility-based metric. However, it would be worth exploring explicitly the case where the social objective function involves not only utility-based welfare but also a measure of financial stability or crisis (such as the leverage ratio or the probability of bank failure), of direct concern to the regulator. This extended welfare criterion may generate an optimal policy that strikes a different balance between the costs of capital requirements (lower investment and welfare) and its benefits (reduced risk-taking by banks and increased financial stability). However, to the extent that it translates into an optimal capital adequacy ratio that is similar, or possibly higher, than what would obtain with a pure utilitybased criterion, the risk of disintermediation alluded to earlier would remain.

Supplementary Information The online version contains supplementary material available at https://doi. org/10.1007/s11149-021-09438-z.

Open Access This article is licensed under a Creative Commons Attribution 4.0 International License, which permits use, sharing, adaptation, distribution and reproduction in any medium or format, as long as you give appropriate credit to the original author(s) and the source, provide a link to the Creative Commons licence, and indicate if changes were made. The images or other third party material in this article are included in the article's Creative Commons licence, unless indicated otherwise in a credit line to the material. If material is not included in the article's Creative Commons licence and your intended use is not permitted by statutory regulation or exceeds the permitted use, you will need to obtain permission directly from the copyright holder. To view a copy of this licence, visit http://creativecommons.org/licenses/by/4.0/.

\section{References}

Acharya, Viral V., Mehran, Hamid, \& Thakor, Anjan V. (2016). Caught between Scylla and Charybdis? Regulating Bank Leverage when there is Rent Seeking and Risk Shifting, Review of Corporate Finance Studies, 5, 36-75.

Agénor, Pierre-Richard. (2019). Growth and welfare effects of macroprudential regulation. Macroeconomic Dynamics, 23, 3140-62.

Allen, Franklin, Carletti, Elena, \& Marquez, Robert. (2011). Credit market competition and capital regulation. Review of Financial Studies, 24, 983-1018.

Basel Committee on Banking Supervision, Basel III: A Global Regulatory Framework for more Resilient Banks and Banking Systems, Report No. 189 (revised, June 2011).

Begenau, Juliane. (March 2015). Capital Requirements, Risk Choice, and Liquidity Provision in a Business Cycle Model, Working Paper No. 15-072, Harvard Business School.

Begenau, Juliane, \& Landvoigt, Tim. (July 2016). Financial Regulation in a Quantitative Model of the Modern Banking System, Working Paper No. 16-140, Harvard Business School.

Blum, Jurg. (1999). Do capital adequacy requirements reduce risks in banking? Journal of Banking and Finance, 23, 755-71.

Boissay, Frederic, \& Collard, Fabrice. (December 2016). Macroeconomics of Bank Capital and Liquidity Regulations, Working Paper No. 596, Bank for International Settlements. 
Cecchetti, Stephen G. (December 2014). The Jury is in, Policy Insight No. 76, Centre for Economic Policy Research.

Christensen, Ian, Meh, Césaire., \& Moran, Kevin. (December 2011). Bank Leverage Regulation and Macroeconomic Dynamics, Working Paper No. 2011-32, Bank of Canada.

Collard, Fabrice, Dellas, Harris, Diba, Behzad, \& Loisel, Olivier. (2017). Optimal monetary and prudential policies. American Economic Journal: Macroeconomics, 9, 40-87.

Dagher, Jihad, Dell' Ariccia, Giovanni, Laeven, Luc, Ratnovski, Lev, \& Tong, Hui. (March 2016). Benefits and Costs of Bank Capital, Staff Discussion Note No. 16/04, International Monetary Fund.

la Croix, De. (2002). David, \& Michel, Philippe. A Theory of Economic Growth: Dynamics and Policy in Overlapping Generations. Cambridge University Press.

DellAriccia, Giovanni, Laeven, Luc, \& Marquez, Robert. (2014). Real interest rates, leverage, and bank risk-taking. Journal of Economic Theory, 149, 65-99.

Dell'Ariccia, Giovanni, Laeven, Luc, \& Marquez, Robert. (2014). Bank Competition and Financial Stability: A General Equilibrium Exposition. unpublished, International Monetary 31 Fund (August 2012). 149, $65-99$.

Diamond, Douglas, \& Rajan, Raghuram. (2000). A theory of bank capital. Journal of Finance, 55, 2431-65.

Foulis, Angus, Nelson, Benjamin, \& Tanaka, Misa. (2019). Credit traps and macroprudential leverage. Journal of Money, Credit, and Banking, 51, 1963-98.

Fratzscher, Marcel, König, Philipp J., \& Lambert, Claudia. (2016). Credit provision and banking stability after the great financial crisis: The role of bank regulation and the quality of governance. Journal of International Money and Finance, 66, 113-35.

Gale, Douglas, Notes on Optimal Capital Regulation, in The Evolving Financial System and Public Policy, ed. by Pierre St-Amant and Carolyn Wilkins, Bank of Canada (Ottawa: 2004).

Gale, Douglas. (2010). Capital regulation and risk sharing. International Journal of Central Banking, 6, 187-204.

Gambacorta, Leonardo, \& Shin, Hyun Song. (2018). Why bank capital matters for monetary policy. Journal of Financial Intermediation, 35, 17-29.

Gersbach, Hans. (2013). Bank capital and the optimal capital structure of an economy. European Economic Review, 64, 241-55.

Gorton, Gary, \& Winton, Andrew. (2017). Liquidity provision, bank capital, and the macroeconomy. Journal of Money, Credit and Banking, 49, 5-27.

Hakenes, Hendrik, \& Schnabel, Isabel. (2011). Capital regulation, bank competition, and financial stability. Economics Letters, 113, 256-58.

Hellmann, Thomas F., Murdock, Kevin C., \& Stiglitz, Joseph E. (2000). Liberalization, moral hazard in banking, and prudential regulation: Are capital requirements enough? American Economic Review, 90, 147-65.

Holmström, Bengt, \& Tirole, Jean. (1997). Financial intermediation, loanable funds, and the real sector. Quarterly Journal of Economics, 112, 663-91.

Klomp, Jeroen, \& de Haan, Jakob. (2014). Bank regulation, the quality of institutions, and banking risk in emerging and developing countries: An empirical analysis. Emerging Markets Finance and Trade, 50, $19-40$.

Kopecky, Kenneth J., \& VanHoose, David. (2006). Capital regulation, heterogeneous monitoring costs, and aggregate loan quality. Journal of Banking and Finance, 30, 2235-55.

Laeven, Luc, \& Levine, Ross. (2009). Bank governance, regulation and risk taking. Journal of Financial Economics, 93, 259-75.

Malherbe, Frederic, (July 2015). Optimal Capital Requirements over the Business and Financial Cycles, Working Paper No. 1830, European Central Bank.

Martinez-Miera, David, \& Suarez, Javier. Martinez-Miera, David, \& Javier Suarez (September 2014) Banks' Endogenous Systemic Risk Taking, unpublished, Universidad Carlos III.

Nguyen, Thien. (March 2015). Bank Capital Requirements: A Quantitative Analysis, Fisher College of Business Working Paper 2015-03-14, Ohio State University.

Repullo, Rafael. (2004). Capital requirements, market power, and risk-taking in banking. Journal of Financial Intermediation, 13, 156-82.

Rochet, Jean-Charles. (1992). Capital requirements and the behaviour of commercial banks. European Economic Review, 36, 1137-78.

Tanaka, Misa, \& Vourdas, John. (May 2016). Equity, Debt and Moral Hazard: The Optimal Structure of Banks' Loss Absorbing Capacity, unpunlished, Bank of England. 
Smith, Acosta, Jonathan, Grill, Michael, Lang, Jan Hannes. (June 2017). The Leverage Ratio, Risk-taking and Bank Stability, Working Paper No. 2079, European Central Bank.

den Heuvel, Van, \& Skander, J. (2008). The welfare cost of bank capital requirements. Journal of Monetary Economics, 55, 298-320.

Van den Heuvel, \& Skander, J. (June 2018). The Welfare Effects of Bank Liquidity and Capital Requirements, unpublished, Federal Reserve Board.

Publisher's Note Springer Nature remains neutral with regard to jurisdictional claims in published maps and institutional affiliations. 